\title{
Collagen membrane versus platelet rich fibrin membrane in bone graft healing: An experimental study in sheep
}

\author{
Mahdi O. Abdullah ${ }^{(1)}$; Ahmed A. Hayder ${ }^{(1)}$
}

\begin{abstract}
Background and objectives: Guided bone regeneration is a term used to define the use of barrier membranes to promote complete osteogenesis. The aim of study was to histologically compare the effect of platelet rich fibrin membrane and resorbable Collagen membrane on bone substitute healing.

Methods: in this experimental study three sheep's which their weighted between 60-70 kg were used. After intramuscular sedation and local anesthesia, eighteen defects were created about $8 \mathrm{~mm}$ in diameter and $5 \mathrm{~mm}$ in depth in the lower border of mandible. Six defects on each animal which three in right side and three in left side of the mandible. The defects were filled with Biphasic calcium phosphate bone substitute. The first defect was covered by platelet rich fibrin membrane, the second one covered by Collagen membrane, and third one was left uncovered. The animals were sacrificed at 2, 6, and 12 weeks.

Results: The healing of the grafted defects was histologically studied in all groups, and there was non-significant difference between PRF membrane and collagen membrane in healing of bone substitute at 2,6 , and 12 weeks. There was significant deference between PRF membrane and collagen membrane at 6 weekregarding scaffold replacement with mature bone.
\end{abstract}

Conclusion: The use of PRF membrane shows a good outcome as a low cost biological material capable of improving bone healing defects, grafted with bone substitute.

Keywords: Platelet rich fibrin membrane, collagen membrane, bone graft, bone healing.

\footnotetext{
${ }^{(1)}$ Department of Oral and Maxillofacial Surgery, College of Dentistry, Hawler Medical University, Erbil, Iraqi Kurdistan Region.
}

\section{Introduction}

Rehabilitation of edentulism using osseointegrated implants has modernized the field of dentistry. Nevertheless, bone loss or deficiency, as a symbol of several systemic and periodontal diseases, trauma, and tumors, remains a major challenge for osseointegration. To achieve a good long -term prognosis for osseointegrated implants, an adequate volume of bone should exist at the sites of implantation. Different approaches, such as bone-grafting techniques, alveolar distraction, and guided bone regeneration (GBR), have been used to reconstruct the lost bone to allow the implant to be fully osseointegrated and preserved during functional loading.

Guided bone regeneration GBR is a term used to define the use of barrier membranes to promote complete osteogenesis by avoiding the quick ingrowth of fibroblasts into a bony defect and stimulating the migration of osteogenic cells from the adjacent bony walls or bone marrow into the defect site in an unimpeded manner, ${ }^{2}$ Over the years, a variety of additional parameters including space maintenance, ability to form a blood clot, cellular infiltration potential, mechanical stabilization, biocompatibility, and resorption properties have been investigated to achieve more favorable bone tissue healing.

Collagen membranes are resorbable biological membrane and normally used for GBR, Collagen is the principal component 
of connective tissue and provides structural support for tissues throughout the body. Collagen is hemostatic agent and possesses the ability to stimulate platelet attachment and to enhance fibrin linkage, which may facilitate initial clot formation and clot stabilization, leading to enhanced regeneration, Collagen has been shown to be chemotactic for fibroblasts in surgical field. This property could enhance cell migration in the surgical field, Collagen can be easily manipulated and adapted, collagen had been demonstrated to be a weak immunogenic and is therefore well tolerated by patients. Membranes made of bovine collagen do not elicit an antibody response when used in GBR, and slowly absorbed. ${ }^{4,5}$ Unpredictable resorption time is one of the main drawbacks of resorbable membranes, which directly disturbs new bone formation, absence of space maintenance ability/ rigidity, high costs, probability for creating a foreign body reaction, and risk of infection if left uncovered to the oral cavity are other disadvantages of collagen membrane. $^{6}$

Platelet rich fibrin PRF is a secondgeneration platelet rich plasma PRP where autologous platelets and leucocytes are present in a complex fibrin matrix, composed of a tetra molecular structure, with cytokines, platelets, and stem cells within it, which acts as a biodegradable scaffold that favors the development of micro-vascularization and is able to guide epithelial cell migration to the surgical field. $^{7,8}$

Platelet rich fibrin PRF is rich of cells involved in tissue regeneration and seems to have a continued release of growth factors, stimulating the environment for wound healing in a reliable amount of time. It has a complex architecture of strong fibrin matrix with favorable mechanical properties and is slowly remodeled. PRF is a healing biomaterial which plays an important role in bone and soft tissue regeneration, without inflammatory reactions and may be used $\mathrm{u}$ alone or in combination with bone grafts. PRF has a great role in hemostasis, bone growth, and maturation. ${ }^{9}$

In this study, PRF was chosen as a membrane because it's biological, easily prepared, cheap and auto graft material, to compare it to a commonly used resorbable collagen membrane.

The aim of this study was to evaluate the efficacy of platelet rich fibrin as guided bone regeneration GBR membrane and compare it histologically with resorbable collagen membrane in the healing of bone defects grafted with bone substitute

\section{Materials and methods}

\section{Animal model and surgical procedure.}

A Comparative, prospective, experimental study is carried out on sheep with a mean weight of $60 \mathrm{~kg}$ and age range 3 to 4 years. The study is conducted at the department of oral and maxillofacial surgery, college of dentistry, Hawler Medical University and veterinary theater (Qoshtapa Veterinary Center-Erbil-Iraq). The study was extended from September 2018 to September 2019 including data collection, entering \& analysis. The study was approved by the Ethical Committee of Hawler Medical University.

Six rounded defects of $8 \mathrm{~mm}$ in diameter and $5 \mathrm{~mm}$ depth were created surgically. Three defects in the right and three in left side of the basal bone of mandible of each sheep. All defects are filled with osteon ${ }^{\mathrm{TM}}$ II bone graft. Before surgery all animals were fasted for 24 hours for food and 12 hours for water one of the reasons veterinarians fast most animals pre-operatively is the risk of vomiting during surgery or recovery.

The surgical procedures were performed under intramuscular sedation and local anesthesia. The animals were sedated using Ketamine hydrochloride $5 \mathrm{mg} / \mathrm{kg}$ (KETALROM-50, S.C ROMVAC company, Ilfov,Romania) and xylazine $0.2 \mathrm{mg} / \mathrm{kg}$ (xyla; metaalweg 8, CG ventery, the Netherland), and $0.2 \mathrm{mg} / \mathrm{kg}$ local anesthesia consisting of Lidocaine Hydrochloride $2 \%$ and Epinephrine 1:100,000 (Novocol Pharmaceutical, Ontario, Canada) are administered in the surgical area. Surgical area was clipped, shaved, washed, and disinfected with povidone-iodine (Betadine, 
Egypt). The lateral side of the basal bone of mandible was exposed via a long incision followed by a separate and blind dissection and elevation of the skin and the facial layers. The bone graft recipient site defects were created by the aim of a surgical trephine bur $8 \mathrm{~mm}$ in diameter and to a depth of $5 \mathrm{~mm}$ along with high torque slow speed surgical hand piece with continuous copious irrigation. Three defects were created on each side of mandibular basal bone and filled with bone graft substitute (Osteon ${ }^{\mathrm{TM}} \mathrm{II}, 0.5 \mathrm{mg}$ ).

First defect was covered by PRF membrane, the second defect was covered by resorbable collagen membrane (Genoss Collagen membrane(GCM), size $15 \mathrm{x}$ $20 \mathrm{~mm}$ ) and the third defect was left uncovered (Figure 1), finally surgical site was sutured.

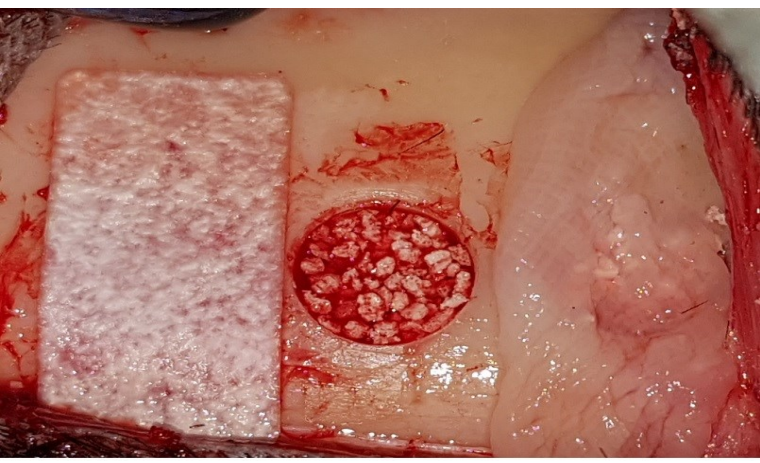

Figure 1: Clinical view of surgical defects

The animals were followed up, the surgical area disinfected by iodine and antibiotics amoxicillin with clavulanic acid (betamox LA) $0.1 \mathrm{ml} / \mathrm{kg}$ once daily with analgesic (NP ANALGIN-Vietnam) contain Analgin $0.1 \mathrm{ml} / \mathrm{kg} 1$ time daily for seven days postoperatively. They take the same food like the other sheep in the farm postoperatively during the 12 week of follow-up.

The animals were sacrificed at 2, 6, and 12 weeks, The Mandible bone was carefully dissected free from soft tissues, and hardtissue samples were transferred into $10 \%$ buffered-formalin solution and underwent histological evaluation.
PRF Membrane preparation. Blood sample is taken without anticoagulant in 10$\mathrm{mL}$ tubes in a glass or glass-coated plastic tube, then immediately centrifuged at 3,000 rpm for 10 minutes. The resultant product consists of the following three layers: upper layer consisting of acellular plasma, middle layer PRF clot, and lower layer red corpuscle at the base of tube. Clot is transformed into a membrane through the compression in a specific tool.10as shown in Figure 2.
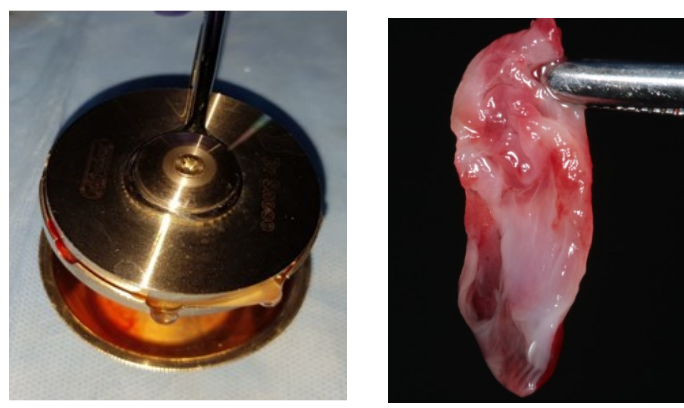

Figure 2: PRF membrane and PRF squeezing tool

Histological evaluation. Histologically, examinations were achieved with one blind histopathologist. All specimens were embedded in $10 \%$ buffered formalin for 1 week. Then all specimens were embedded with $50 \%$ formic acid and 20\% sodium citrate solution for decalcification. The decalcified specimens were set in paraffin and cut in to $3 \mu \mathrm{m}$ thick sections (LeicaMicrosystemicRM2125, Leica, Berlin, Germany), and routine hematoxylin and eosin staining was performed.

The defect cut from center and cut surfaces of both sides is rotated to top, to see depth and surface of defect at same slide. The sections were examined with a light microscope (Olympus, Tokyo, Japan).

Each defect was examined from peripheral or central according to criteria cited by Revista Română. ${ }^{11}$ with this criteria the histological bone formation is scored as follow: $0=$ absent; $1=$ Present at peripherally; $2=$ Present at centrally; $3=$ Present centrally and peripherally. The data collected is categorical. The parameters for examining slides are: Bone formation, $\mathrm{mm}$ 
Scaffold replaced by mature bone, new blood vessel formation.Chi square test used to find out the association and P-value was $>0.05$.

\section{Results}

Bone formation. Histologically, according to Table 1 , there was no significant difference among study groups. At week 2 bone formation found in center of defect that covered by collagen membrane, while in defect covered by PRF membrane and control group found in center and periphery of defect. At week 6 and 12, reveled the same results, because readings show bone formation in all defects in center and periphery (Figure 3 ). Scaffold replaced by mature bone Table 2 shows that at week 2 there is no scaffold replaced with mature bone among the three study groups, so the significant difference was not applicable statistically, while at week 6 histological readings showed replacement at the periphery of the defects covered by collagen membrane, but defects covered with PRF membrane replacement was found in the center and in the control group there was no scaffold replacement with mature bone. There is significant difference between groups at week $6(\mathrm{P}$-value $=0.01)$. At week 12 all defects showed scaffold replacement with mature bone at the center and periphery, with no significant difference being noted (Figure 4).

New blood vessel formation. As shown in Table 3, at week 2 there was new blood vessel formation at the center and the periphery of defects that covered with PRF membrane, while in defects covered with collagen membrane only showed blood vessels at center. There was no significant difference between the three groups $(p=$ value $=0.06)$. At week 6 and 12 , there was new blood vessels at center and periphery of at the three defects, with no significant difference among the groups being noted.

Table 1: Comparison between the study groups in bone formation at weeks two, six and twelve.

\begin{tabular}{|c|c|c|c|c|c|}
\hline \multirow[b]{2}{*}{ Bone formation } & \multirow[b]{2}{*}{ Categories } & \multicolumn{3}{|c|}{ Study groups } & \multirow[b]{2}{*}{$\boldsymbol{P}$} \\
\hline & & $\begin{array}{l}\text { Bone graft cov- } \\
\text { ered with Colla- } \\
\text { gen membrane }\end{array}$ & $\begin{array}{l}\text { Bone graft } \\
\text { covered with } \\
\text { PRF mem- } \\
\text { brane }\end{array}$ & $\begin{array}{c}\text { Bone graft } \\
\text { alone }\end{array}$ & \\
\hline \multirow{4}{*}{ week 2} & Absent & $0(0 \%)$ & $0(0 \%)$ & $0(0 \%)$ & \multirow{4}{*}{0.06} \\
\hline & Center & $2(100 \%)$ & $0(0 \%)$ & $0(0 \%)$ & \\
\hline & Periphery & $0(0 \%)$ & $0(0 \%)$ & $0(0 \%)$ & \\
\hline & Center and periphery & $0(0 \%)$ & $2(100 \%)$ & $2(100 \%)$ & \\
\hline \multirow{4}{*}{ week 6} & Absent & $0(0 \%)$ & $0(0 \%)$ & $0(0 \%)$ & \multirow{4}{*}{ NA } \\
\hline & Center & $0(0 \%)$ & $0(0 \%)$ & $0(0 \%)$ & \\
\hline & Periphery & $0(0 \%)$ & $0(0 \%)$ & $0(0 \%)$ & \\
\hline & Center and periphery & $2(100 \%)$ & $2(100 \%)$ & $2(100 \%)$ & \\
\hline \multirow{4}{*}{ week 12} & Absent & $0(0 \%)$ & $0(0 \%)$ & $0(0 \%)$ & \multirow{4}{*}{ NA } \\
\hline & Center & $0(0 \%)$ & $0(0 \%)$ & $0(0 \%)$ & \\
\hline & Periphery & $0(0 \%)$ & $0(0 \%)$ & $0(0 \%)$ & \\
\hline & Center and periphery & $2(100 \%)$ & $2(100 \%)$ & $2(100 \%)$ & \\
\hline
\end{tabular}




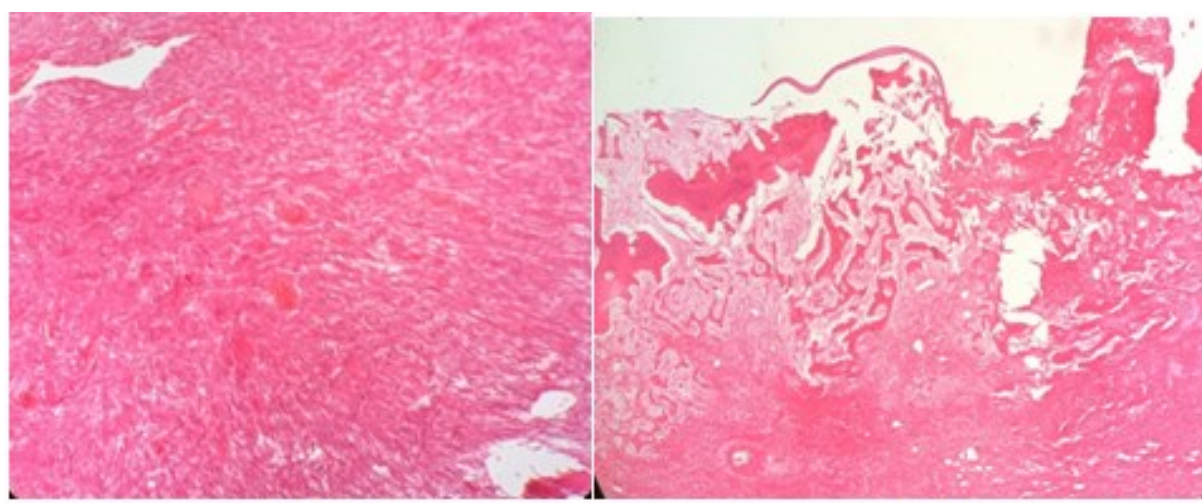

A

B

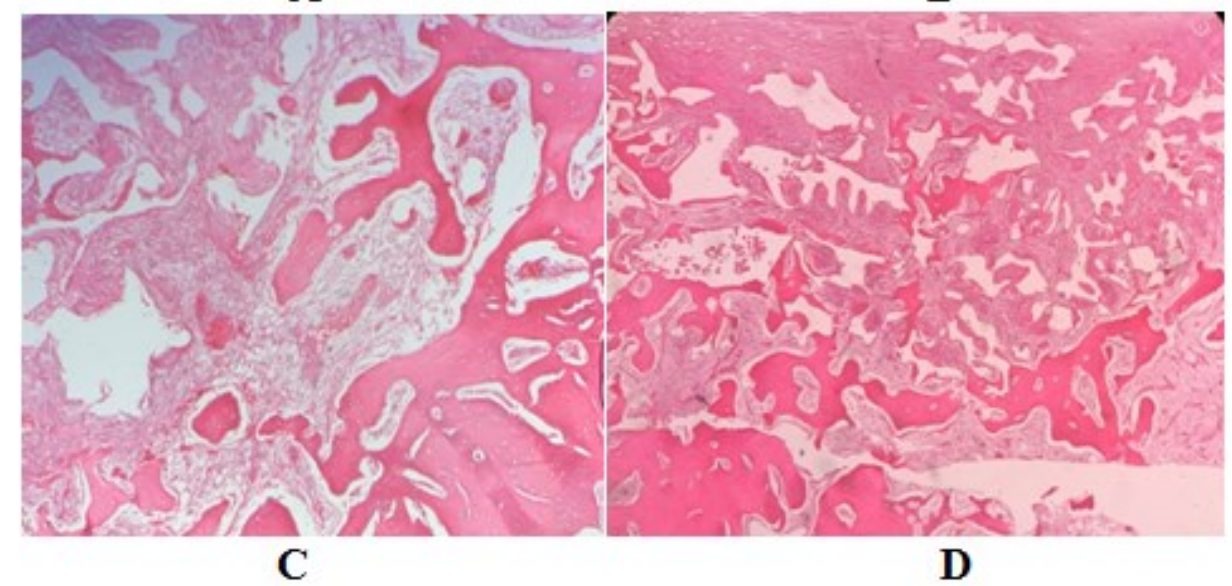

C

D

Figure 3: Bone formation, A- Collagen membrane at 2 week, B- PRF membrane at 2 week, C- Collagen membrane at 6 week, D- PRF membrane at 6 week. (Power 10x for each slide)

Table 2: Comparison betweenthe study groups inscaffold replaced with mature bone at weeks two, six and twelve weeks.

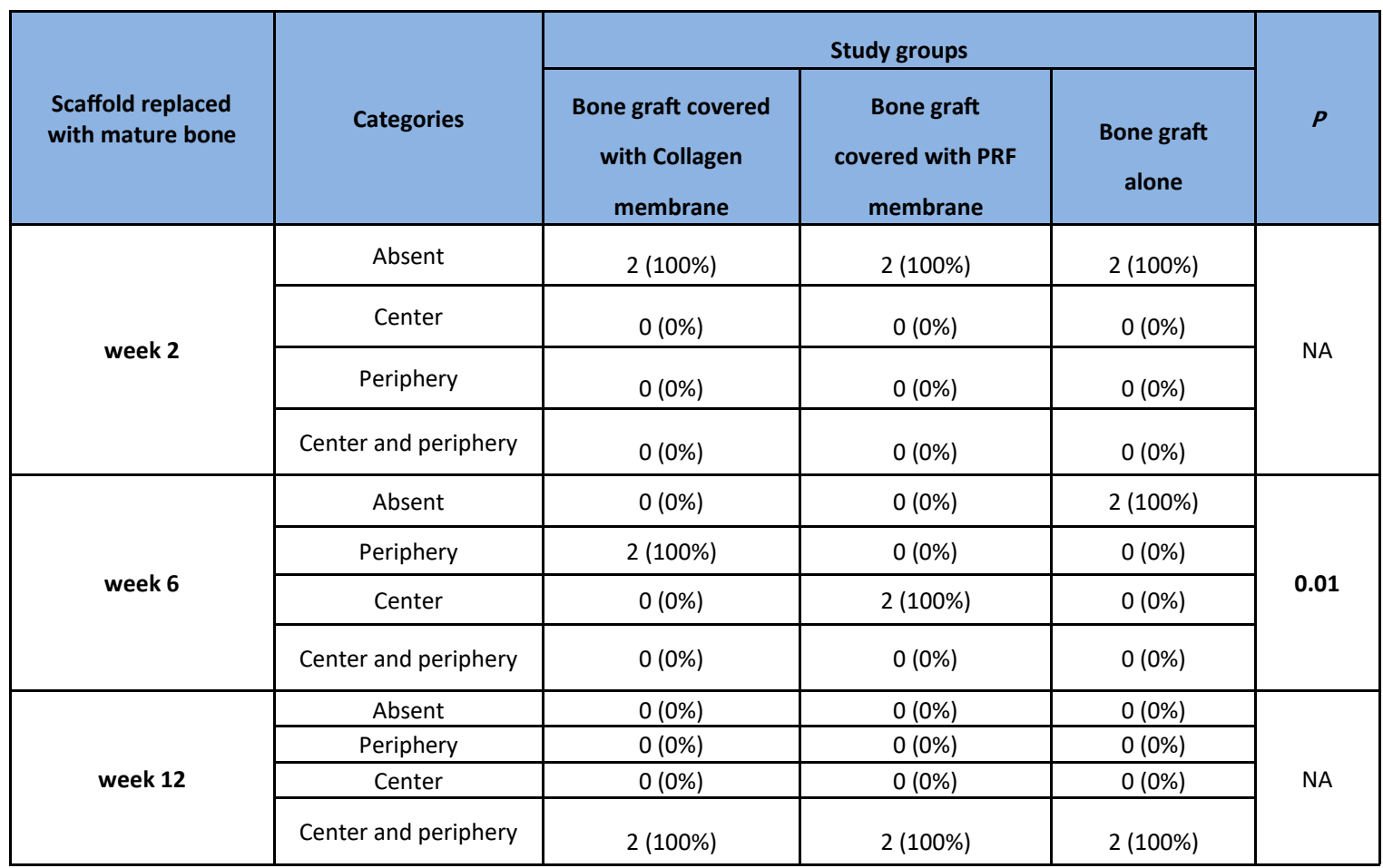




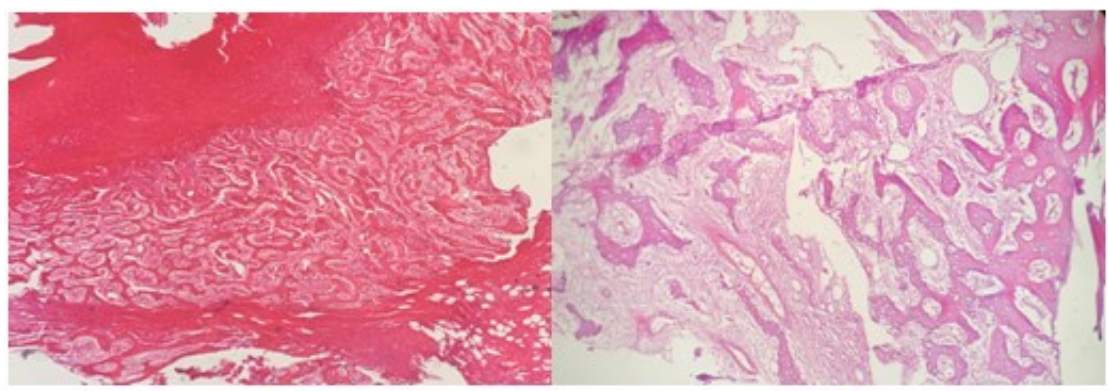

A

B

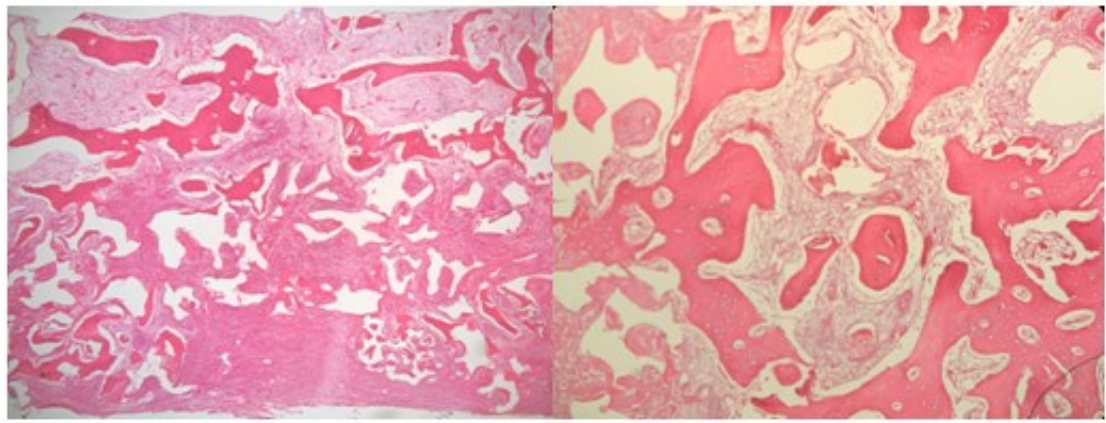

C

D

Figure 4: Scaffold replacement by bone graft: A- Collagen membrane at 2 week, B- PRF membrane at 2 week, C- Collagen membrane at 6 week, D- PRF membrane at 6 week. (Power10x for each slide)

Table 3: New blood vessels formation at two, six and twelve weeks of follow up.

\begin{tabular}{|c|c|c|c|c|c|}
\hline \multirow[b]{2}{*}{$\begin{array}{l}\text { New blood } \\
\text { vessels } \\
\text { formation }\end{array}$} & \multirow[b]{2}{*}{ Categories } & \multicolumn{3}{|c|}{ Study groups } & \multirow[b]{2}{*}{$P$} \\
\hline & & $\begin{array}{c}\text { Bone graft covered } \\
\text { with Collagen } \\
\text { membrane }\end{array}$ & $\begin{array}{c}\text { Bone graft cov- } \\
\text { ered with PRF } \\
\text { membrane }\end{array}$ & $\begin{array}{c}\text { Bone graft } \\
\text { alone }\end{array}$ & \\
\hline \multirow{4}{*}{ week 2} & Absent & $0(0 \%)$ & $0(0 \%)$ & $0(0 \%)$ & \multirow{4}{*}{0.06} \\
\hline & Center & $2(100 \%)$ & $0(0 \%)$ & $2(100 \%)$ & \\
\hline & Periphery & $0(0 \%)$ & $0(0 \%)$ & $0(0 \%)$ & \\
\hline & Center and periphery & $0(0 \%)$ & $2(100 \%)$ & $0(0 \%)$ & \\
\hline \multirow{4}{*}{ week 6} & Absent & $0(0 \%)$ & $0(0 \%)$ & $0(0 \%)$ & \multirow{4}{*}{ NA } \\
\hline & Center & $0(0 \%)$ & $0(0 \%)$ & $0(0 \%)$ & \\
\hline & Periphery & $0(0 \%)$ & $0(0 \%)$ & $0(0 \%)$ & \\
\hline & Center and periphery & $2(100 \%)$ & $2(100 \%)$ & $2(100 \%)$ & \\
\hline \multirow{4}{*}{ week 12} & Absent & $0(0 \%)$ & $0(0 \%)$ & $0(0 \%)$ & \multirow{4}{*}{ NA } \\
\hline & Center & $0(0 \%)$ & $0(0 \%)$ & $0(0 \%)$ & \\
\hline & Periphery & $0(0 \%)$ & $0(0 \%)$ & $0(0 \%)$ & \\
\hline & Center and periphery & 2 (100\%) & 2 (100\%) & 2 (100\%) & \\
\hline
\end{tabular}




\section{Discussion}

The aim of this histological study was to evaluate the effect of PRF membrane on bone substitute healing and compare it with that of collagen membrane, the results shows the new bone formation in both groups seems to be similar at 12 week follow up, while bone formation at 2 week to be more evident in PRF membrane coated defect. Therefor the use of PRF membrane accelerates bone substitute healing and allow implant placement at earlier time in compare with collagen membrane.

This study agrees with Choukrone et al (2006) ${ }^{12}$ who concluded that the use of PRF in combination with freeze dried bone allograft to augment sinus floor elevation enhanced bone regeneration in shorter time and accelerate healing of sinus membrane perforation in histological point of view. Olaereha and Mendoza (2016) $)^{13}$ compared the clinical and histological features of two collagen membranes (Bio Gide and Bio-MendExtend) for their effect on implant dehiscence defects in dogs. After four weeks no significant differences were observed between the groups; however, at four months a higher linear percentage of bone fill in large areas was observed. It was concluded that treatment with collagen membranes can stimulate bone regeneration significantly during later stages (four months), similar to present study which show collagen membrane effect on bone substitute healing at 12 weeks.

PRF membrane application must be applied as early as possible to the surgical site to ensure the maximum release of growth factors and the produced exudate after squeezing of the PRF clot can be used for hydration of bone substitute which can provide additional growth factor. ${ }^{14}$

In this present studynew blood vessel formed more rapidly in PRF membrane at 2 weeks, it seems that PRF promot angiogenesis. This result was found also by Uchida et $\mathrm{al}^{15}$ and Steinbrech et al ${ }^{16}$ demonstrated that new blood vessels in wound healing is critical in the delivering nutrients, oxygen and crucial cells from nearby tissues in hypoxic surgical defect, and vascular endothelial growth factor is in authority to regulate angiogenesis in the healing of sur- gically created defect.

PRF membrane also favor scaffold replacement in the present study at 6 weeks of follow up which is similar to that of Gassling et al (2010) ${ }^{17}$ who conducted that PRF membrane superior to collagen membrane in the healing of scaffold and enhance periosteal cell proliferation in surgically created defects

Because the study conducted on small sample size and the criteria for histological reading are categorical, same results as for bone formation and new blood vessels formation at 12 weeks, showed similar results. So statistically P-value was not applicable.

\section{Conclusion}

The use of PRF membrane has gained incredible outcome as a low cost biological material capable of improving bone healing.

\section{Conflict of interests}

The authors reports no conflict of interests.

\section{REFERENCE}

1. Elgali, I., Omar, O., Dahlin, C., \& Thomsen, P. Guided bone regeneration: materials and biological mechanisms revisited. European journal of oral sciences, 2017. 125(5), 315-337.

2. Özan, F., Şençimen, M., Gülses, A., \& Ayna, M. Guided bone regeneration technique using hyaluronic acid in oral implantology. A Textbook of Advanced Oral and Maxillofacial Surgery: Volume 3. 2016, 3343.

3. Toffler, M. Guided bone regeneration (GBR) using cortical bone pins in combination with leukocyte-and platelet-rich fibrin (L-PRF). Compend Contin Educ Dent, 2014. 35(3): p. 1928.

4. Lee, S.-W. and S.-G. Kim. Membranes for the guided bone regeneration. Maxillofacial plastic and reconstructive surgery. 2014. 36(6):239-246.

5. Wang, H.-L. and W.J. Carroll. Guided bone regeneration using bone grafts and collagen membranes. Quintessence international, 2001. 32(7). 
6. Salamanca, E., Tsai, C. Y., Pan, Y. H., Lin, Y. T., Huang, H. M., Teng, N. C., ... \& Chang, W. J. In vitro and in vivo study of a novel porcine collagen membrane for guided bone regeneration. Materials, 2016. 9(11), 949.

7. Varela, H. A., Oliveira, M. N., Pereira, J., Souza, J. C. M., Pinto, N., \& Quirynen, M. Chapter 7 - Platelet-rich fibrin to incorporate bioactive graft materials, in Nanostructured Biomaterials for CranioMaxillofacial and Oral Applications, J.C.M. Souza, et al., Editors. 2018, Elsevier. p. 119-142

8. Castro AB, Meschi N, Temmerman A, Pinto N, Lambrechts $P$, Teughels $W$, Quirynen $M$. Regenerative potential of leucocyte-and platelet-rich fibrin. Part B: sinus floor elevation, alveolar ridge preservation and implant therapy. A systematic review. Journal of clinical periodontology. 2017; 44(2):225-34.

9. Borie, E., Oliví, D. G., Orsi, I. A., Garlet, K., Weber, B., Beltrán, V., \& Fuentes, R. Platelet-rich fibrin application in dentistry: a literature review. International journal of clinical and experimental medicine, 2015. 8(5), 7922.

10. Mazor, Z., Horowitz, R. A., Del Corso, M., Prasad, H. S., Rohrer, M. D., \& Dohan Ehrenfest, D. M. Sinus floor augmentation with simultaneous implant placement using Choukroun's platelet-rich fibrin as the sole grafting material: a radiologic and histologic study at 6 months. Journal of periodontology, 2009 . 80(12), 2056-2064.

11. Lucaciu, O., Gheban, D., Soriţau, O., Băciuţ, M., Câmpian, R. S., \& Băciuţ, G. Comparative assessment of bone regeneration by histometry and a histological scoring system / Evaluarea comparativă a regenerării osoase utilizând histometria și un scor de vindecare histologică. Romanian Review of Laboratory Medicine, 2015. 23(1).

12. Choukroun, J., Diss, A., Simonpieri, A., Girard, M. O., Schoeffler, C., Dohan, S. L., ... \& Dohan, D. M . Platelet-rich fibrin (PRF): A second-generation platelet concentrate. Part V: Histologic evaluations of PRF effects on bone allograft maturation in sinus lift. Oral Surg Oral Med Oral Pathol Oral Radiol Endod, 2006. 101(3):299-303.

13. Olaechea, A., Mendoza-Azpur, G., Valdivia, E., \& Rasperini, G . Biodegradation of three different collagen membranes: A histological study. J of Osseointeg. 2016. 8(2):15-9.

14. Su, C. Y., Kuo, Y. P., Tseng, Y. H., Su, C. H., \& Burnouf, $T$. In vitro release of growth factors from platelet-rich fibrin (PRF): a proposal to optimize the clinical applications of PRF. Oral Surg Oral Med Oral Pathol Oral Radiol Endod. 2009. 108(1):56-61.
15. Uchida, S., Sakai, A., Kudo, H., Otomo, H., Watanuki, M., Tanaka, M., ... \& Nakamura, T. Vascular endothelial growth factor is expressed along with its receptors during the healing process of bone and bone marrow after drill-hole injury in rats. Bone. 2003. 32(5):491-501.

16. Steinbrech, D. S., Mehrara, B. J., Saadeh, P. B., Greenwald, J. A., Spector, J. A., Gittes, G. K., \& Longaker, M. T . VEGF expression in an osteoblast -like cell line is regulated by a hypoxia response mechanism. American Journal of Physiology-Cell Physiology, 2000. 278(4):C853-C860.

17. Gassling, V., Douglas, T., Warnke, P. H., Açil, Y., Wiltfang, J., \& Becker, S. T . Platelet-rich fibrin membranes as scaffolds for periosteal tissue engineering. Clin Oral Implants Res, 2010. 21(5):5439. 